\title{
Mitomycin Regimen
}

National Cancer Institute

\section{Source}

National Cancer Institute. Mitomycin Regimen. NCI Thesaurus. Code C160087.

A chemotherapy regimen consisting of mitomycin that may be used in the treatment of bladder cancers and for radiosensitization in cervical cancers. 